DOI: $10.14451 / 1.181 .369$

\title{
ФАКТОРЫ, ОКАЗЫВАЮЩИЕ ВЛИЯНИЕ НА РАЗВИТИЕ СТРОИТЕЛЬСТВА РОССИИ И КИТАЯ
}

\author{
(c) 2019 Цзинчэнь Юй \\ аспирант \\ Санкт-Петербургский государственный экономический университет, Россия, Санкт-Петербург \\ E-mail: may_9171@mail.ru
}

В статье представлен анализ внешних и внутренних факторов, оказывающих влияние на развитие строительства России и Китая. Основываясь на структуре и динамике рынка строительства России и Китая, были определены основные аспекты его развития.

Ключевые слова: строительство, строительный рынок, факторы развития строительства, экономический рост России, экономический рост Китая

Строительство толкуется как сооружение нового объекта, реконструкция, расширение, достройка, реставрация и ремонт объектов, выполнение монтажных работ; полный комплекс деятельности по сооружению объектов; все виды строительных работ, в том числе капитальные, гражданское строительство, монтаж и демонтаж строений и конструкций; составная часть комплекса работ, связанных с созданием объекта архитектуры. В то же время ряд нормативно-правовых актов оперирует прежде всего правовой категорией «строительство» и всеми процессами, которые с ним связаны [1].

Перспективы развития мирового строительного рынка обуславливаются общей конъюнктурой изменения объемов мировой экономики. Учитывая оценки экспертов, перелом негативной тенденции снижения темпов экономического роста и возвращение к к устойчивому росту глобальной экономики в ближайшее время невозможны. Среднегодовые темпы роста 5,4\% (в восстановительный период после 2010 г.) пока остаются лишь в воображении. После посткризисного восстановления в 2010 году со среднегодовым темпом 5,4\% мировая экономика на протяжении пятилетнего периода закрепилась на нисходящей траектории роста. Так, в 2017 году рост мировой экономики составил в 3,6\% при некотором увеличении темпов роста развитых стран с до 2,2\% [2].

По оценкам международных экспертов организаций Global Construction Perspectives и Oxford Economics объем мирового строительного сектора к 2030 году вырастет на 85\% по сравнению с 2016 г. и достигнет уровня 17,5 трлн. долл. США. Данный прогноз основывается на том, что благодаря продолжающейся индустриализации национальных экономик стран Юго-Восточной Азии и восстановления экономики США, после резкого спада в период финансового кризиса, мировой рынок строительных услуг, будет расти более быстрыми темпами, чем объем изменения мирового ВВП. В следующем десятилетии будет наблюдаться продолжающийся сдвиг объемов инвестиций в сторону быстро растущих строительных рынков Юго-Восточной Азии и других стран с развивающимися экономиками, где рост населения, быстрая урбанизация и высокие темпы экономического роста станут основными драйверами для строительства [3].

Прогноз роста мирового строительного производства в 2019 году был пересмотрен до 2,7\%, минимальным за последние десять лет.

Показатель роста был пересмотрен в сторону понижения из-за падения на развивающихся рынках, а также в США и на Ближнем Востоке.

Однако, согласно прогнозу GlobalData, рост мирового строительного производства увеличится до 3,2\% в 2020 году, а затем стабилизируется на уровне $3,4 \%$ в течение оставшейся части прогнозного периода, который длится до 2023 года.

В Китае, где власти наращивают инвестиции в инфраструктуру, чтобы предотвратить дальнейшее замедление, рост будет оставаться положительным, способствуя небольшому ускорению роста общего объема производства на развивающихся рынках.

Усиливаются геополитические риски, которые потенциально могут подорвать доверие инвесторов и нарушить движение капитала в начале прогнозного периода.

Политическая неопределенность не способствует росту мировой строительной индустрии. Юго-Восточная Азия, по прогнозам, будет са- 
мым быстрорастущим регионом в период 20192023 годов, наблюдая рост на 6,4\% [4].

Строительная отрасль в Китае будет демонстрировать рост примерно на 4,5\% в течение следующих пяти лет до 2023 года.

В четвертом квартале 2017 года строительная активность в Китае выросла на 6,1\%, подталкивая рост за год до $4,5 \%$. Это ниже двузначного роста, которым этот сектор пользовался ранее.

Инвестиции в крупномасштабные инфраструктурные проекты были ключевой частью стратегии китайского правительства по стимулированию роста. Отчасти именно по этой причине ожидается, что рост останется на относительно низком уровне в $4,5 \%$.

Прогнозируемые темпы роста строительства
Китая представлены на рис. 2.

Однако прогнозирование спроса в Китае всегда является сложной задачей, поскольку правительство склонно вмешиваться, чтобы стимулировать или охлаждать экономику, как оно считает нужным. Если экономический рост замедлится, он может использовать инвестиции в строительство в качестве инструмента для увеличения роста, и это может вызвать еще один всплеск активности. И наоборот, если экономика перегреется и инфляция начнет расти, она может нацелиться на сектор недвижимости и строительства с мерами по замедлению роста [5].

Основные экономические показатели по виду деятельности «Строительство» Китая за 2009-2017 гг. представлены в таблице 1.

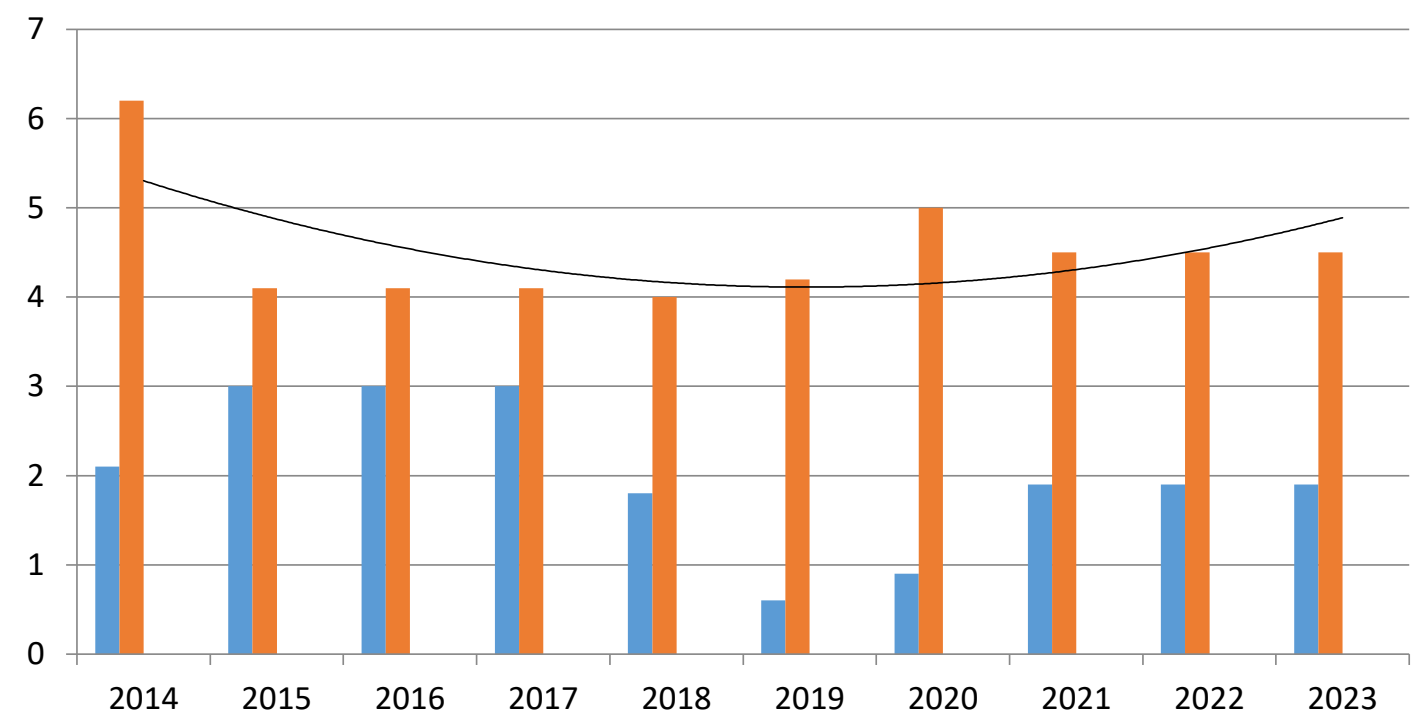

Рисунок 1. Мировой объем производства строительных работ GlobalData

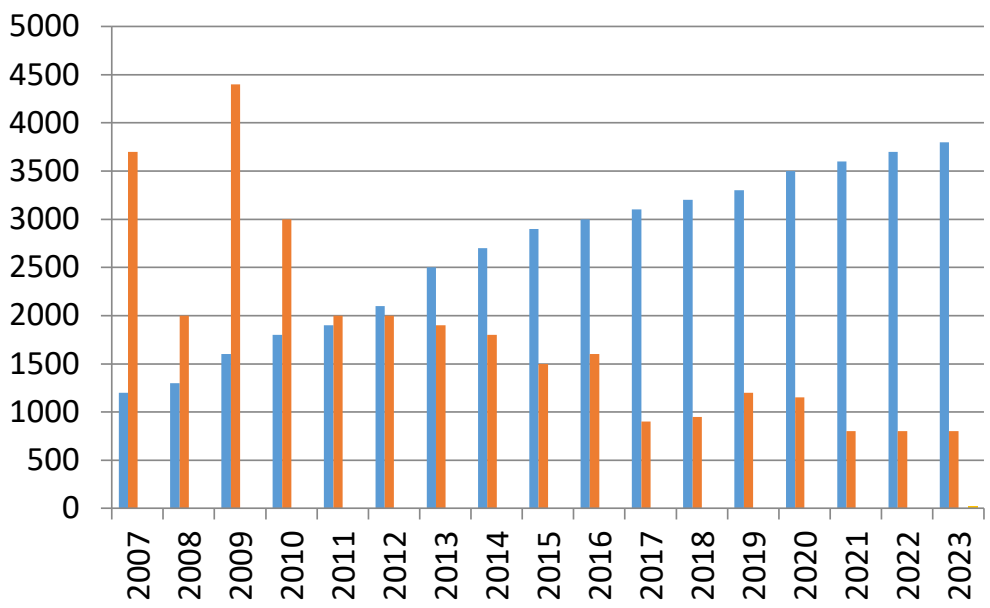

выходное значение (млрд. дол.)

рост производства (\%)

Рисунок 2. Прогнозируемые темпы роста строительства Китая GlobalData 
Таблица 1. Основные экономические показатели по виду деятельности «Строительство» Китая за 2009-2017 гг. [6]

\begin{tabular}{|c|c|c|c|c|c|c|c|c|c|}
\hline & 2009 & 2010 & 2011 & 2012 & 2013 & 2014 & 2015 & 2016 & 2017 \\
\hline $\begin{array}{c}\text { Количество } \\
\text { строительных } \\
\text { предприятий } \\
\text { (единица) }\end{array}$ & 70,817 & 71,863 & 72,280 & 72,280 & 78,919 & 81,141 & 80,911 & 83,017 & 88,074 \\
\hline $\begin{array}{c}\text { Численность } \\
\text { занятых на } \\
\text { строительных } \\
\text { предприятиях } \\
\text { (10000 чело- } \\
\text { век) }\end{array}$ & 3672,56 & 4160,44 & 3852,47 & 4267,24 & $4,528,36$ & 4536,97 & 5093,67 & 5184,50 & 5529,63 \\
\hline $\begin{array}{c}\text { Основные } \\
\text { средства (пер- } \\
\text { воначальная } \\
\text { стоимость) на } \\
\text { строительство } \\
\text { предприятий } \\
\text { (100 миллио- } \\
\text { нов юаней) }\end{array}$ & 11,63138 & 12847,77 & 14059,60 & $15,476.93$ & & $17,940.31$ & 18,82320 & 18,97984 & 19,97440 \\
\hline $\begin{array}{c}\text { Основные } \\
\text { средства } \\
\text { (чистая сто- } \\
\text { имость) на } \\
\text { строительных } \\
\text { предприятиях } \\
\text { (100 миллио- } \\
\text { нов юаней) }\end{array}$ & 7591,92 & 8299,90 & 8889,91 & 9582,58 & & 10630,41 & 10862,39 & 10655,56 & 11089,34 \\
\hline $\begin{array}{c}\text { Количество } \\
\text { машин и } \\
\text { оборудова- } \\
\text { ния, при- } \\
\text { надлежащих } \\
\text { строительным } \\
\text { предприятиям } \\
\text { на конец года } \\
\text { (комплект) }\end{array}$ & $9,734,910$ & $11,209,484$ & $10,054,231$ & $10,157,280$ & $11,467,280$ & $12,030,587$ & $9,643,725$ & $9,643,725$ & $9,579,327$ \\
\hline $\begin{array}{c}\text { Валовая } \\
\text { стоимость } \\
\text { строительства } \\
\text { предприятий } \\
\text { (100 миллио- } \\
\text { нов юаней) }\end{array}$ & $76,807.74$ & $96,031.13$ & 116463,32 & 137217,86 & 160366,06 & 176713,42 & 180757,47 & 193566,78 & 213943,56 \\
\hline $\begin{array}{c}\text { Добавленная } \\
\text { стоимость } \\
\text { строительства } \\
\text { (100 миллио- } \\
\text { нов юаней) }\end{array}$ & 1919,80 & 18983,50 & 22071,00 & 26583,31 & 33071,50 & 35270,15 & 36064,70 & 37626,80 & 39765,33 \\
\hline $\begin{array}{c}\text { Амортизация } \\
\text { основных } \\
\text { средств на } \\
\text { строительство } \\
\text { предприятий } \\
\text { (100 миллио- } \\
\text { нов юаней) }\end{array}$ & 756,31 & 916,76 & 956,78 & 1065,47 & & 1165,47 & 1182,12 & 1177,98 & 1202,11 \\
\hline $\begin{array}{c}\text { Заработная } \\
\text { плата на } \\
\text { строительных } \\
\text { предприяти- } \\
\text { ях (100 млн. } \\
\text { юаней) }\end{array}$ & 8151,78 & $12,556.79$ & $15,603.95$ & 21296,96 & & $21,296.96$ & $21,805.37$ & $22,929.84$ & 24099,14 \\
\hline
\end{tabular}


Согласно таблице 1 , наблюдается тенденция роста всех основных экономических показателей по виду деятельности «Строительство» в Китае. Количество строительных предприятий в 2009 г. составляло 70,817 ед. В 2011-2012 гг., оно оставалось неизменным составляя 70,817 ед. В 2015 г. численность строительных предприятий уменьшилась относительно 2014 г., с 81,141 ед. до 80,911 ед. С 2016 г. количество снова стало расти.

Численность занятых на строительных предприятиях в 2009 г. составляла 3672,56 чел. В 2010 г., следовательно - 4160,44 чел., что свидетельствует об увеличении. В 2011 г. количество занятых уменьшилось практически до уровня 2009 г. С 2012 г. по 2017 г. наблюдалась положительная тенденция роста средней численности занятых на строительных предприятиях до 5529,63 чел.

Основные средства (первоначальная стоимость) на строительство предприятий в 2009 г. составляли 11,63138 млн. юаней. В 2017 г.19,97440 млн. юаней. С 2009 по 2017 гг. первоначальная стоимость росла.

Основные средства (чистая стоимость) на строительных предприятиях в 2017 г. составила 11089,34 млн. юаней.

Количество машин и оборудования, принадлежащих строительным предприятиям, на конец 2009 г. составило 9,734,910 ед, 2010 г.11,209,484, 2011 г.- 10,054,231 ед. Рекордное количество составило 12,030,587 ед. на конец 2014 года. В 2017 г. наблюдалось наименьшее количество - 9,579,327 ед.

Валовая стоимость строительства предприятий увеличилась с 76,807,74 млн. юаней в 2009 г. до 213943,56 млн. юаней в 2017 г.

Добавленная стоимость строительства росла с каждым годом с 1919,80 млн. юаней в 2009 г. до 39765,33 млн. юаней в 2017 г. Незначительное падение наблюдалось лишь в 2010 г.

Амортизация основных средств на строительство предприятий в 2009 г. составляла 1202,11 млн. юаней, и следовательно в 2017 г. составила 1202,11 млн. юаней, что свидетельствует о тенденции увеличения с каждым годом.

Заработная плата на строительных предприятиях возросла с 2009 г. по 2017 г. на 15947,36 млн. юаней. И в 2017 г. составила 24099,14 млн. юаней.

Экономический рост Российской Федерации в 2018 г.: ВВП вырос на 2\%. Вклад строительства в рост ВВП в 2018 г. составил 0,3 п.П. Оно повысило оценку годового роста ВВП в I квартале 2018 г. до 1,8\% с 1,3\%, во втором - до 2,2\% с 1,9\%, в третьем оставило прежней $-1,5 \%$, в четвертом, по его оценке, экономика выросла на 2,2\%.

В период с 2014 по 2017 гг. российская строительная отрасли значительно сократилась. Объем производства сократился на 2,3\% в 2014 году. При этом ситуация в отрасли в последние несколько лет ухудшалась. Если в 2015 году наблюдалось сокращение объема производства на $4,8 \%$, то в 2016 году падение составило уже $4,8 \%$ Кроме того, негативная тенденция продолжилась и в 2017 году [7].

Основные экономические показатели по виду деятельности «Строительство» Российской Федерации представлены на рисунке 3.

Согласно данных рисунка 3 в 2017 г., такие показатели как объем выполненных работ, среднегодовая численность занятых в строительстве, среднемесячная номинальная начисленная заработная плата работников строительства, наличие основных фондов в строительстве растут. Объем инвестиций в основной капитал, направленные на развитие строительства снизился, а такие показатели как удельный вес основных фондов строительства в общей стоимости основных фондов, и степень износа основных фондов в строительстве (на конец года) остались без изменений.

Число действующих строительных организаций, согласно таблице 2 , с каждым годом росло. В 2005 г. оно составляло 112846 ед. В 2017 г.279496 ед., что на 166650 ед. больше. В 2017 г., количество микропредприятий не значительно уменьшилось в сравнении с 2016 г. на 5213 ед., но в сравнении с 2010 г. увеличилось на 79068 ед.

Структура работ, выполненных организациями собственными силами по виду экономической деятельности «Строительство» в 2017 г. представлена в таблице 3.

Согласно таблице 3 строительство инженерных сооружений, а также строительство зданий (жилых и нежилых) занимают наибольший удельный вес в строительстве. Наименьший, в свою очередь, занимают работы строительные отделочные, всего $0,7 \%$.

Согласно таблице 4 и рисунка 4 , можно сделать вывод, что строительная отрасль России, анализируя динамику валовой добавленной стоимости, развивается более быстрыми темпами, чем строительная отрасль Китая. С 1990 г. до 


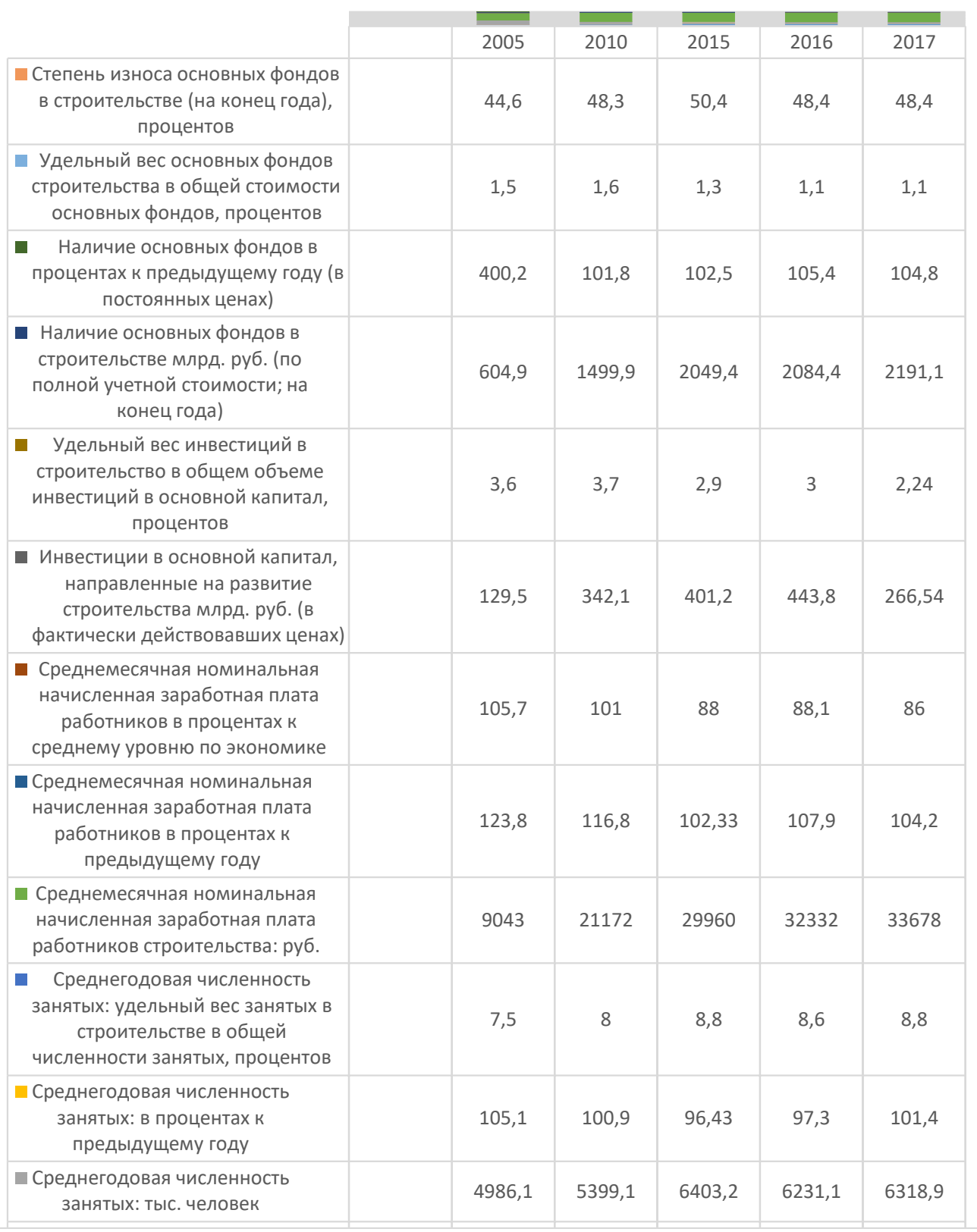

Рисунок 3. Основные экономические показатели по виду деятельности «Строительство» Российской Федерации 2005-2017 гг. [8]

Таблица 2. Число действующих строительных организаций [8]

\begin{tabular}{|c|c|c|c|}
\hline \multirow{2}{*}{ Годы } & \multirow{2}{*}{$\begin{array}{c}\text { Число строительных } \\
\text { организаций - всего }\end{array}$} & $\begin{array}{c}\text { вубъектов малого пред- } \\
\text { принимательства (включая } \\
\text { микропредприятия) }\end{array}$ & из них микропредприятия \\
\hline 2005 & 112846 & 102162 & - \\
\hline 2010 & 196234 & 186195 & 156428 \\
\hline 2011 & 209185 & 200643 & 170414 \\
\hline 2012 & 205075 & 195836 & 179947 \\
\hline 2013 & 217961 & 208993 & 189981 \\
\hline 2014 & 226838 & 217968 & 199532 \\
\hline 2015 & 235351 & 227452 & 240709 \\
\hline 2016 & 271604 & 262129 & 235496 \\
\hline 2017 & 279496 & 262403 & \\
\hline
\end{tabular}


Таблица 3. Структура работ, выполненных организациями собственными силами по виду экономической деятельности «Строительство» [8] в 2017 г.

\begin{tabular}{|l|c|}
\hline & В процентах к итогу* \\
\hline Строительство - всего & 100 \\
\hline в том числе: & 35,2 \\
\hline строительство зданий (жилых и нежилых) & 40,4 \\
\hline строительство инженерных сооружений & 25,0 \\
\hline из него строительство автомобильных и железных дорог & 11,1 \\
\hline строительство инженерных коммуникаций & 4,3 \\
\hline строительство прочих инженерных сооружений & 24,4 \\
\hline работы строительные специализированные & 7,2 \\
\hline в том числе: & 9,1 \\
\hline разборка и снос зданий, подготовка строительного участка & 0,7 \\
\hline $\begin{array}{l}\text { производство электромонтажных, санитарно-технических } \\
\text { и прочих строительно-монтажных работ }\end{array}$ & 7,4 \\
\hline работы строительные отделочные & \\
\hline работы строительные специализированные прочие & \\
\hline
\end{tabular}

*без субъектов малого предпринимательства

Таблица 4. Валовая добавленная стоимость по виду экономической деятельности «Строительство» Российской Федерации и Китая в 1990-2017 г.г.

\begin{tabular}{|c|c|c|c|c|c|c|c|c|c|c|c|}
\hline Страна & 1990 & 2000 & 2005 & 2010 & 2011 & 2012 & 2013 & 2014 & 2015 & 2016 & 2017 \\
\hline Россия & 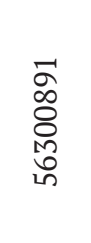 & 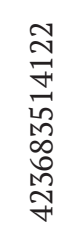 & 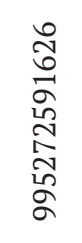 & 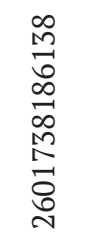 & 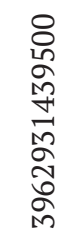 & 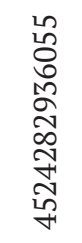 & 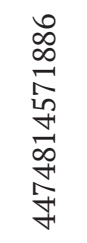 & 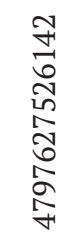 & 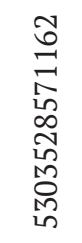 & 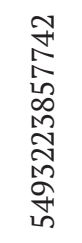 & 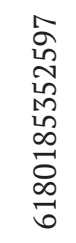 \\
\hline Китай & 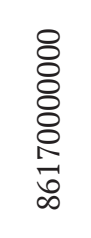 & $\begin{array}{l}8 \\
8 \\
8 \\
8 \\
8 \\
8 \\
\text { 언 } \\
\text { nㅡㄴ }\end{array}$ & $\begin{array}{l}8 \\
8 \\
8 \\
8 \\
8 \\
8 \\
\text { 눙 } \\
8 \\
\text { 임 }\end{array}$ & 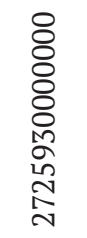 & 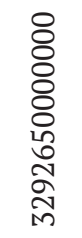 & 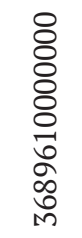 & 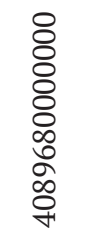 & 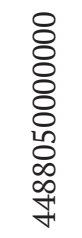 & 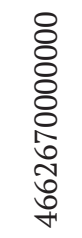 & 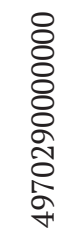 & $\begin{array}{l}8 \\
8 \\
8 \\
8 \\
8 \\
8 \\
8 \\
8 \\
\infty \\
\text { ᄂ } \\
\text { 10 }\end{array}$ \\
\hline
\end{tabular}

Составлено автором.

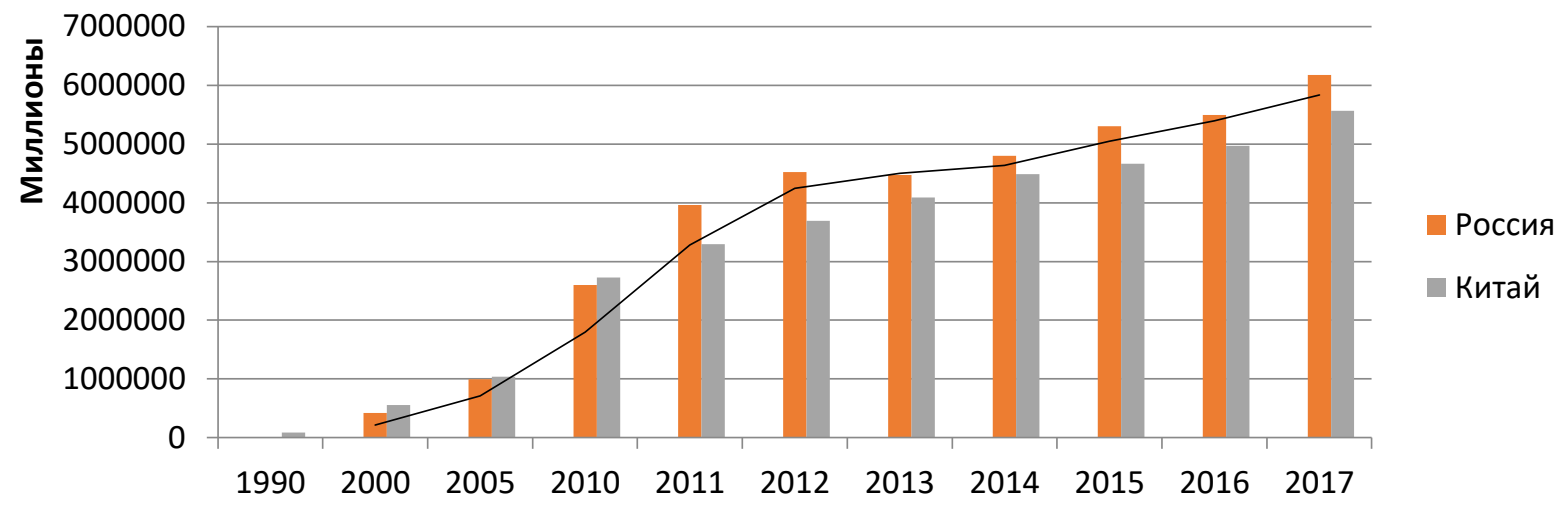

Рисунок 4. Динамика валовой добавленной стоимости по виду экономической деятельности «Строительство» Российской Федерации и Китая в 1990-2017 гг.

Составлено автором. 
2010 г. темпы роста валовой добавленной стоимости Китая опережали темпы роста валовой добавленной стоимости Российской Федерации. С 2011 г. валовая добавленная стоимость России значительно превышала валовую добавленную стоимость Китая.

Факторы, которые ограничивают промышленную деятельность строительных организаций в Российской Федерации представлены на рис. 5.

Исходя из анализа влияния на деятельность строительных организаций Российской Федерации, представленного на рисунке 5 , можно сделать вывод, что динамика влияния недостатка материалов и нехватка, а также изношенность строительных машин и механизмов оказывают наиболее низкое влияние в период 2017-2018 гг. Наиболее высокий уровень влияния оказывают налоги, в частности, их высокий уровень негативно влияет на динамику развития деятельности строительных организаций России. Такое же негативное влияние оказывает высокая

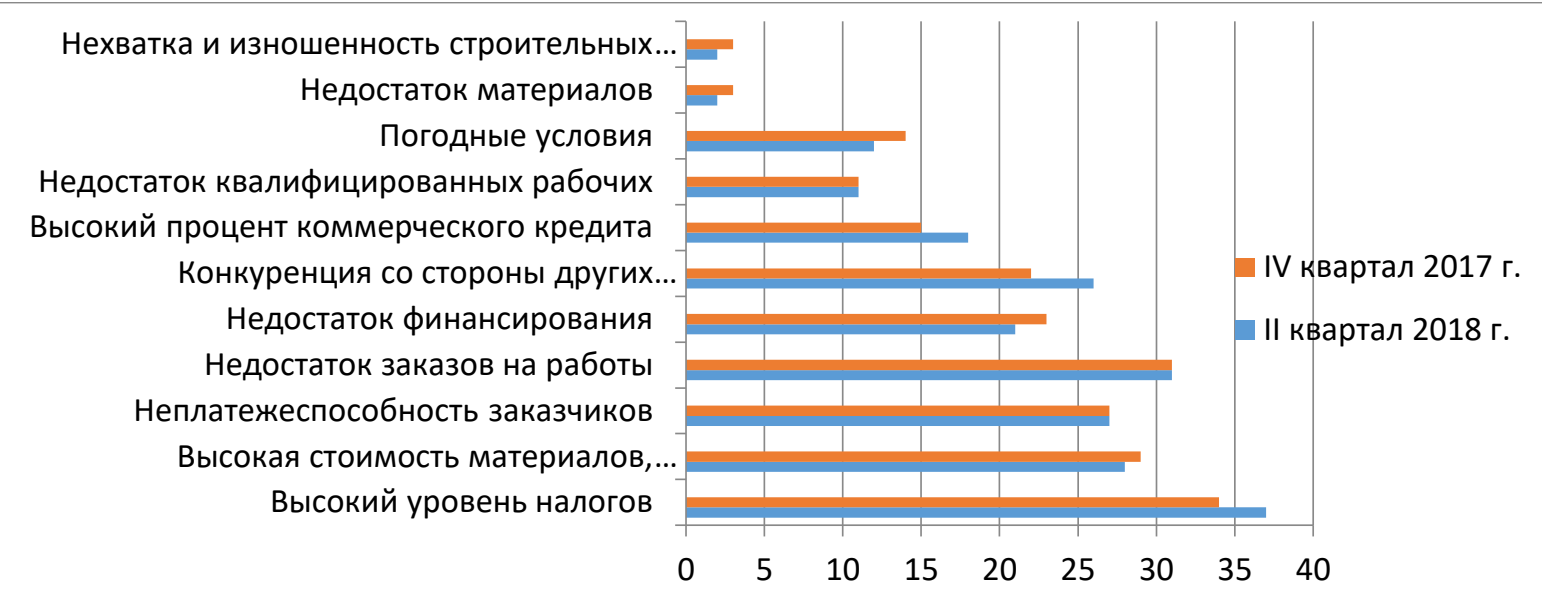

Рисунок 5. Факторы, ограничивающие производственную деятельность строительных организаций [8]
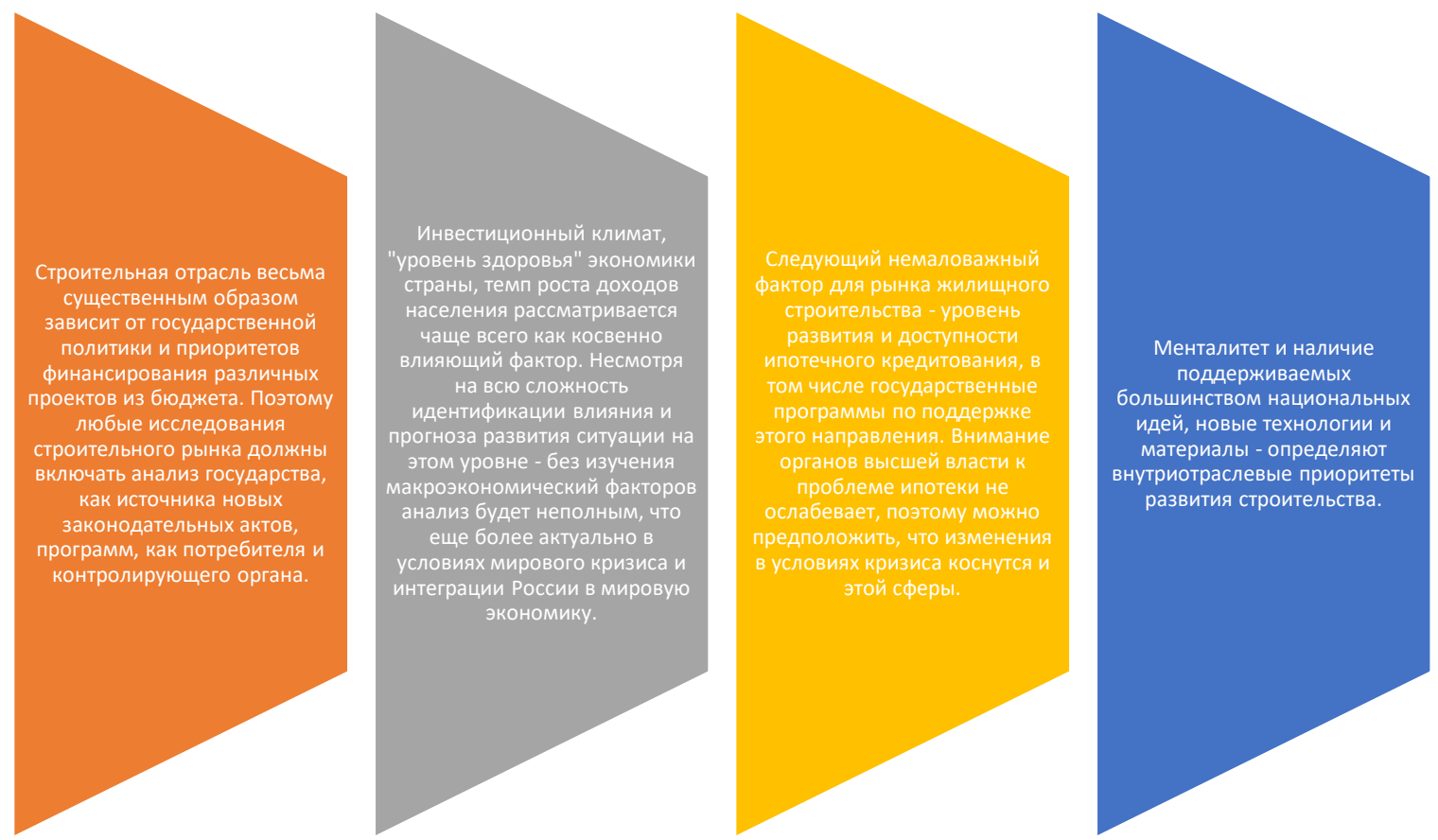

Рисунок 6. Факторы, оказывающие влияние на деятельность строительных организаций в России и Китае [9] 
стоимость материалов, конструкций, изделий. Учитывая эти данные, можно отметить, что снижение уровня налогов и стоимости вышепредставленных товаров приведет к активизации деятельности строительных организаций России.

Факторы, влияющие на строительную отрасль, необходимые для изучения при анализе строительного рынка включают представлен-

\section{Библиографический список}

1. Стукаленко О. Теоретические аспекты определения дефиниций «строительство» и «капитальное строительство».- Административное право № 3.-2016.- с. 103-106.

2. Неравномерность развития стран мира. Бюллетень о текущих тенденциях мировой экономики. Март 2018 года, № 30-М.: Аналитический Центр при Правительстве Российской Федерации. 2018. http://ac.gov.ru/files/ publication/a/16434.pdf

3. общемировые тенденции и современные вызовы развития строительства.- URL: https://budexport.by/ world_market.php

4. Global construction growth to slow. - URL: https://www.khl.com/international-construction/global-constructiongrowth-to-slow/140490.article

5. China's construction market growth to slow.- URL: https://www.khl.com/international-construction/chinasconstruction-market-growth-to-slow/137183.article.

6. Показатели по виду деятельности «Строительство» Китая. - URL: http:/data.stats.gov.cn/english/easyquery. htm?cn=C01

7. Russian construction industry set to drop 3\% in 2018. - URL: https://www.pmrmarketexperts.com/en/russianconstruction-industry-set-to-drop-3-in-2018/.

8. Строительство в России. 2018: Стат. сб. / Росстат.-М., С863 2018.- 119 с.

9. Анализ строительной отрасли и рынка строительных материалов. URL: http://id-marketing.ru/about/uslugi/ obzori-rinka-id-marketing/analiz-stroitelnogo-rinka 